\title{
An Analysis of the Status of women Leadership in Education Sector of the catchment areas of Wolaita Sodo University
}

\author{
Tafano Ouke Labiso \\ Assistant Professor, \\ Educational Leadership and Management
}

\begin{abstract}
The purpose of this study was to investigate causes for the underrepresentation of women in top positions of the education sector of the catchment areas of Wolaita Sodo University. Hence, to realize this purpose, secondary school teachers, principals of secondary schools, and supervisors of all levels, and heads of education offices and departments of Dawro and Wolaita administrative zones were used as the target population. In order to make the study manageable, the sample secondary schools teachers were selected by simple random sampling technique, and principals and supervisors were selected through purposive sampling techniques. Descriptive survey research design and concurrent mixed approaches were applied. Both close-ended and open-ended questionnaires and unstructured interviews were used to collect data. Frequency counts, and percentages were employed for quantitative data through closeended questionnaire. Data through qualitative questionnaire were narrated and used for the sake of triangulation. The finding showed that women were underrepresented due to self-related factors, socio-cultural factors, institutional factors, economic factors, and political-legal factors in the leadership positions of secondary and primary schools, principal ship positions, and supervisory positions. Thus, it was concluded that though the Federal Democratic Republic of Ethiopia has taken a number of affirmative actions and stipulated the issue of empowering women in the constitution, yet women were strikingly underrepresented in Dawro and Wolaita zones of south Ethiopia, particularly in the education sector. Therefore, it was recommended that taking into account that women are half the population, talented in leadership and management and the advantage of gender diversity in educational leadership institutions, government and the large society should strive towards empowering women.
\end{abstract}

Key words: underrepresentation, women, women leadership, leadership

\section{INTRODUCTION}

Women and the previously disadvantaged or minority groups in the country are not involved in management or leadership of educational institutions, particularly in the developing countries of the world in general and in Africa in particular(Udo, 2011; Wells, 2009;Dencker, 2008). And also they were and are seldom exposed to these management and leadership positions and not developed adequately to function effectively in leadership and management positions of the education sector. In some countries there was no gender sensitive policies and conventions and exclusive policies and ideologies in some cases some decades ago (including Ethiopia)(MoE, 2014). However, it is evident that since 1990s a number of international, regional, and national policies and conventions have been designed to bring women to leadership and management positions and to other social sectors (Tyson, 2012). Yet, there is still an imbalance and the progress of equity is very slow and uneven in Ethiopia in general and Dawro and Wolaita administrative zones in education sectors (WDZEDs, 2017). In this regard, Nkomo and Ngambi(2009) argue that African potential women leaders are missing from leadership agendum. Jameson (2010) also adds to this saying "women are still significantly "held back" in global equality terms according to a range of indicators, as if they literally have 
one hand behind their backs while fighting a (visible and invisible)battle to achieve gender equality. This is particularly true in east African countries like Ethiopia (MoE, 2011). Though more women are now joining schools and universities as students, administrative workers at precarious job positions, and even as teachers, however, the number of women in leadership and management positions and in high paying job positions in schools, districts, and zones is still in significant (Ngunjiri, 2010; MoE,2016). In Dawro and Wolaita zones administration cases, for instances, thereare no women heads of schools, districts, and zones, and supervisory positions in a required number as to the annual statistics of the two zones education departments of 2016.

Though empowering women has a number of advantages like economic growth of the country, and family welfare that comes from educating women is undeniable (WB,2009), however, empirical evidences show that there is an insignificant participation of women and accordingly both the zones and the country missed that untapped potential of women. This can be done more when women are empowered in all levels of the education system in general and in lower levels of education like schools, districts, and zone administrations that are bases for education and with more student population (MoE, 2016;;King \&Hill, 1993).

Moreover, according to Forum for African Educationists (FAWE, 2010), women can play significant roles to curb the problems that other women may face both inside and outside of institutions if are empowered. First, their presence as leaders becomes model and has the power of attracting others; and secondly, their presence helps them listen to the problems of other women. Because the degree of intimacy and attachment between and among women leaders and women followers is better than men leaders and women followers in the institutions like schools, district education offices, and zonal education departments. Thus, managing and leading complex and highly diversified educational institutions where there are both male and female students, academics, and administrative staffs in the absence of female leaders and managers is thought to be incomplete. Thus, the untapped leadership potentials of women became area of concern on the part of the researcher.

\section{Statement of the Problem}

Despite all the efforts and affirmative action made by the Federal government of Ethiopia, since 1995, women are still underrepresented in leadership positions of education at different levels in Dawro and Wolaita zones of south Ethiopia. However, it is not clear why women have not taken advantages of the affirmative actions and are absent in leadership positions (MoE, 2014). According to Ulman(2009) having gender diverse point of view in executive management and leadership positions yields a wider and better approach to decision making(Ulman, 2009; Catalyst, 2004). Accordingly, they acknowledge that women need to hold leadership positions and gender diversity should be part of the education system. However, women heads of schools, districts, and administrative zones of Wolaita and Dawro were found to be insignificant despite the aforementioned measures taken by the two governments-the federal and the Regional states.

Yet no adequate studies were made to fill such a gap or no full-fledged solution was found except the general policy formulation of both the Federal and regional governments. In this regard, the absence of women leaders in different educational leadership positions in the two zones not only caused alienation, frustration, and marginalization, but also made retention and recruitment of the future aspiring women leaders more difficult (COOK, 2001; MoE, 2010). This study, therefore was aimed mainly to answer the following basic question- "why is the underrepresentation of women in leadership positions of education at different levels in 
Dawro and Wolaita administrative zones of southern region of Ethiopia?" under this overriding basic question were the following sub questions:

1. What are women themselves-related factors for the underrepresentation of women in leadership positions in Dawro and Wolaita administrative zones?

2. What are the institutional factors that contributed to the underrepresentation of women in the educational leadership positions of Dawro and Wolaita zones?

3. What are the socio-cultural factors?

4. What are the economic factors that hindered women not to climb up the leadership position?

5. What are the political-legal factors that hindered women not to climb up the leadership position?

6. Which factor(s) is(are) the most serious one(s)?

\section{Objectives}

The overriding objective of the study was to investigate the root causes for the underrepresentation of women in educational leadership and management positions in schools, districts, and administrative zones of Dawro and Wolaita zones, south Ethiopia. Towards achieving this main objective the following sub objectives were designed:

1. To investigate the root causes for the underrepresentation of women in different leadership positions in the education sector of Dawro and Wolaita administrative zones of south Ethiopia;

2. To identify the most serious problems that hindered women not to move up the ladder of leadership; and

3. To provide training that may likely contribute to empowering women based on the findings.

\section{Significances}

Close investigation of literature, frequent observations, and the current existing statistics of the two administrative zones and the federal Ministry of education show that there are no sufficient data on the factors affecting the participation of aspiring potential women leaders. Therefore, this study was hoped to provide adequate information to the policy makers, women themselves, institutions and those who are willing to conduct a research later on the same title or topic based on their interest. Furthermore, it is hoped to add to the literature on women leadership. Moreover, the researcher could learn a lot of things while reviewing different literature by different leadership and management gurus.

\section{Scope}

The main purpose of this study was to investigate factors that contributing to the underrepresentation of women in education sector of Dawro and Wolaita administrative zones. The study therefore, is geographically delimited to the two zones education sector of southern Nations, Nationalities, and Peoples Regional States which are the catchment areas of Wolaita Sodo University, and conceptually to the null or low participation of women in the leadership or management positions in the education sector of the two zones of southern Ethiopia.

\section{Concept of Leadership}

\section{LITERATURE REVIEW}

There are many ways to finish the sentence," Leadership is...”. As Stogdill (1974) pointed out in a review of leadership research, there are almost as many different definitions of leadership as there are people who have tried to define it. It is much like the words democracy, love, and peace. Because such words can have different meanings for different people though we 
intuitively know what we mean by such words. Hence, below are different definitions given by different people: Leadership is the art or process of influencing people so that they will strive willingly and enthusiastically towards the achievement of the group's goal (Griffin, 2000). It is influencing of the actions, behaviors, beliefs, and goals of the actor in social system by another actor with the willing cooperation of one actor being influenced (Morphet, 1982). It is initiation of a new structure or procedure for accomplishing the organization's goal and objectives (Hemphil, 1949). Leadership is the ability to persuade others to seek defined objectives enthusiastically (Davis, 1998). It is the human factor that binds a group together and motivates it towards its goals (ibid). It is the process of influencing and supporting others to work enthusiastically towards achieving objectives (McGregor, 1978; Hersey and Blanchard, 1988).

Leadership is the ability to entrust the followers towards a definite goal. It is a process of stimulating members of the group towards particular directions. It is the ability to inspire people to action and the ability to create leaders from followers (Gomez-Mejia, 2003). It is the process of creating excitement in works and developing choices in order to influence people and make all opportunities of change. It is associated with words like risk taking, dynamism, creativity, change, and vision. It is a process of encouraging and helping others to work enthusiastically toward objectives. It is a process whereby one person influences others to do something of their own volition, neither because it is required nor because of the fear of the consequences of non-compliance. It is the influential increment over and above mechanical compliance with routine directives of the organization (J.A. Okumbe). As to Massarik (1961), it is interpersonal influence directed through the communication process towards the attainment of some goals. It is the process of directing and influencing the task-related activities of the group members (Ralph, M. Stogdill, 1974). It is the ability to use different forms of power to influence follower's behaviors in a number of ways. Leadership involves other people (leader-followers). It has unequal distribution of power. It is about values-that gives emphasis about the values of humans. It is the process of evoking the warm and gratifying prospect of being part of a successful team or organization or nation It is the process of doing the right thing other than doing things right. It signifies the talent to bring people together, to get them to work effectively together to meet common goal, to cooperate with each other, to rely upon each other and to trust each other

Leadership is the use of non-coercive influence to shape the group's or organization's goals, motivate behavior towards the achievement of those goals and help define group or organizational culture. It is a process, involves influence, occurs in groups, and involves common goals. Hence, based on these: It is a process whereby one person influences others to do something of their own volition, neither because it is required nor because of the fear of the consequences of non-compliance. It is the influential increment over and above mechanical compliance with routine directives of the organization (J.A. Okumbe). It is interpersonal influence directed through the communication process towards the attainment of some goals (Massarik, 1961). It is the process of directing and influencing the task-related activities of the group members (Ralph, M. Stogdill, 1974). It is the ability to use different forms of power to influence follower's behaviors in a number of ways It involves other people (leader-followers). It has unequal distribution of power. It is about values-that gives emphasis about the values of humans. It is the process of evoking the warm and gratifying prospect of being part of a successful team or organization or nation.

\section{Women and Educational Leadership}

In spite of an increasing association of teaching role with women globally, their presence is conspicuously low in senior educational leadership positions across countries and cultures (Shah, 2012). There are some broadly shared factors such as gender power relations, role 
stereotyping, role socialization, public versus domestic attitude of the society and others leading to such phenomenon. However, it is easy to assume that these factors are constructed and enacted relatively in a similar ways across cultures and societies (Shah, 2012). The prevalent cultural systems and social patterns of behavior determine the discourse shaping the concepts and contexts of each situation. On the other hand, educational leadership is a field of study and practice concerned with the operation of schools and other educational organizations (Bush, 2008). There is a great interest in this educational leadership in this early part of the $21^{\text {st }}$ century. This is because the widespread belief that the quality of leadership makes a significant difference to student outcomes and institutions (Bolam, 2004). According to (Collinson \& Collinson, 2005), there is no space to fully rehearse the very many and contested conceptualizations of leadership in general and educational leadership in particular. It is sufficient here for the sake of this study to distinguish two important aspects of leadership in education. The first is that of providing direction, organizational vision, and making related decisions about resource allocations and distributions. Leaders achieve this in a variety of ways, using different approaches and styles of leadership (Collinson \& Collinso, 2005; Marrelli, 2007). These leadership styles utilize different sources of power and impact differently on the levels and extent to which staff consider them as making contribution to organizational decision making. Both the quality and extent of staff participation in decision making tends to wane as we move across the continuum from laissez-faire to autocratic leadership.

The second aspect of leadership is the issue of control and exerting influence. Both aspects of leadership involve power and the ability to obtain, retain and move resources (Menke \& Ogborn, 1993; Collinson \& Collinso, 2005). Power can be used to enforce decisions and ends that may be desired or undesired by particular individuals or groups. Power can also be shared with the group so that members can have equal participation in decision making. Variations in power distributions in decision making are foundational in the development of numerous concepts of leadership (Fosket \& Lumby, 2003; Brunner, 2002). Accordingly, for leaders in contemporary educational institutions, selecting optimum decision making processes in an increasingly heterogeneous context has become a central concern.

The question of gender in education began to intrigue research and policy attention since last four decades. The interest ever since was to reduce gender disparity in education by promoting equal erudition of females with males. Despite the advocacy and some promising scenario, gender disparity in education is still continuing in favor of males in many countries of the world, particularly in Africa (Bunyi, 2004; FAWE, 2012; Meaza, 2009). The low participation of girls in education in Africa is attributed to many factors which include social and structural impediments such as sexual harassment and gender-blind institutional structures and leadership (FAWE, 2012). In line with this, gender disparity in Education in Ethiopia has started to attract the attention of the government very recently in spite of its prevalence across several educational ladders (Alemu, 2003; Merga, 2016). The higher the educational ladder, the wider the gender disparity in favor of males (including leadership positions)(MoE, 2014; Merga, 2016). Nevertheless, the forms and sources of gender disparity in the country's education sector has got inadequate research consideration (MoE, 2014; Merga, 2016)

\section{Significance of Women Leadership}

According to Harman (2009), having a more diverse management/or leadership team helps avoid identikit thinking and encourages a dynamic mix of perspectives and approaches, which leads to better leadership. Cabera (2009) also states that research findings demonstrated that as more women move into certain sectors of the economy, stereotypes may be evolving in ways that create a more level playing field for women who aspire to leadership positions. Diverse leadership offers organizations a competitive advantage and is a source of strength 
and prosperity for organizations (Catalyst, 2008, 2014; Tinuke, 2011; Christiana et al., 2016). There is a growing body of research that highlight the benefit of work place diversity in general and the specific benefits of diversity in leadership in the HEIs. Improved financial and organizational performance; better connected domestic and global markets; recruitments from global and domestic labor pools; increased creativity and innovations; and enhanced social inclusions are some of the benefits of diversified leadership (Catalyst, 2008, 2013; Suisse, 2012). Diverse leaders also serve as role model shaping the aspirations of younger generations. Diversity is linked to increased performance. Studies suggest that organizations with higher percentage of women on their top management teams perform better financially (McKinsey \& Company, 2007, 2008; Catalyst, 2008, 2013). Diverse teams are more likely to "think outside the box" and come up with innovative solutions to challenges (Certo et al., 2006). A critical mass of women broadens the perspective of boards of directors to better represent the concerns of diverse stakeholders; women are more likely than men to pursue answers to difficult questions; and finally, women tend to bring a more collaborative approach to leadership, thereby improving communication between the board and senior executives (Konrad \& Kramer, 2006;GTA, 2012).The inclusion of women on boards can additionally enhance the public reputations of the organizations they serve(Miller \& Trianna, 2009). Diverse voices are also likely to be more strategically innovative, while senior executive groups which are diverse producers of superior outcomes (Tinuke, 2011; Christiana et al., 2016; Catalyst, 2008, 2013).

\section{Barriers to women Leadership in Education Sector}

The process toward equitable changes should be improved by reducing and implementing current barriers to educational leadership positions. In the UNESCO(2010) study entitled "Women in Education Management" identified the main barriers preventing the participation of women in decision making arena: limited access to education, discriminatory appointment and promotion practices, the stress of dual family and professional roles, family attitudes, career interruptions, cultural stereotyping, alienation from the male culture and continued resistance to women in management positions, propagation of the glass ceiling syndrome which privileges covert criteria for advancement, and absence of adequate policies and legislation to ensure the participation of women. Hence, below are the factors:

\section{Socio-Cultural Barriers}

Gender inequality in educational leadership attributes to broader societal structural inequalities. According to authors like (Cubillo and Brown, 2003; Shakeshaft, 1989) ,women are marginalized in decision making and leadership. Furthermore, Helgeson (2005) points out that women have been socialized in to believing that they do not deserve leadership positions. According to Morely(2006), there are psychological barriers to emerge from the socialization of women as secondary citizens. This affects their agency or ability to act powerfully and independently against oppressive structures. As different researchers show, because of socialization and sex-role stereotyping, women do not immediately connect themselves with any kind of leadership (Shake shaft, 1989).

In the $17^{\text {th }}$ century, women were perceived as intellectually inferior to men and as incapable of being educated (Chliwiniak, 2009). "Her faculties were not worth training. Her place is in the home, where man had assigned her a number of useful functions". Such statements reflect all women of the world regardless of their color, race, religion, etc. on one hand and on the other hand, it clearly shows the male dominance in almost all countries of the world (though the degree varies from country to country. Such negative attitudes and dominance of men towards women excluded them from political, economic, and social activities and limited to domestic 
responsibilities such as house-keeping, child rearing, sewing and cooking(Nidiffer, 2009; Solomon, 2010).

Women leaders also strive for the balance between responsibilities at work and at home (Grogan \&Campbell, 2009). Like men women experience the day-to-day activities of leading as all -consuming, but unlike many men, many women leaders go home to another "day's work" taking care of family and home (Coleman, 2010). Eagly and Carli (2007), adds to this that the impact of family responsibilities on women's careers is high. Women often face the trade-offs between family and career.

Gender, being socially constructed, contributes to the development of a specific social order (Carvalho, 2010). Social constructions that attribute a closer relationship between masculinity and power have been identified as one of the main obstacles women face in getting into top organizational positions.

Morley(2006) has the idea of a "public" versus "private" sphere that is the private sphere(domestic life, home and family)is considered the traditional domain of women, whereas the public sphere (work and politics ) is accepted as the domain of men. This privatepublic dichotomy is deeply ingrained in the law too. The number of women who get in to masculine-oriented occupations, especially in managerial positions, is limited because it is presupposed that women lack the drive, aggressiveness, and leadership ability required for success.

The idea of a 'public' versus a 'private' sphere is another key measure of societies' perception of women's rights. The private sphere (domestic life, home and family) is considered the traditional domain of women. On the other hand, the public sphere (work and politics) is accepted as the domain of men.

Another serious problem regarding their underrepresentation in leadership position is due to the imbalance between the responsibilities of women at home and at work. In this regard, (Brunner,2008; Coleman, 2009; Curry, 2010; Dillard, 2007), argue that like men, women experience the day-to-day activities of leading as all-consuming, but unlike many men, many women leaders go home to another "day's work" taking care of family and home.

Lack of role model parents at home is also found to be another factor for lack of many women leaders. In this regard, Barbara- Curry (2009), goes on to say that when women talk about their female role models in their lives, they often proudly mention their mothers, how much these women had to handle. Such mothers were strong figures who inspired their daughters to later assume the leadership positions.

It is also found to be imperative to bring women to the leadership position if it is thought to play roles in climate change. In this regard, the late Wangari Maathai and Mary Robinson pointed out that "The absence of women from national and international discussions and decision making on climate change and development must change. The battle to protect the environment is not solely about innovation, it is also about empowering women and their communities to hold their governments accountable for their results (WFP, 2010). So, in the light of this, WFP (2010) adds to say that empowering women is a cornerstone of fostering adaptation and addressing the impacts of climate change on nutrition, security, and health. Through drawing on women's knowledge and experiences based on their unique social, economic and resource management roles climate change adaptation planners can significantly reduce communities' vulnerability to climate change. 
Women serve as agents of social change and development through their unique roles in the family and childcare, agricultural labor, food and nutrition security, health and disaster risk reduction. The promotion of their engagement and leadership is critical to addressing the climate change in equitable, healthy and sustainable ways.

\section{Women's Self-Related Barriers}

It is not only the external factors that affect the participation of women in leadership positions, but also women themselves. In this regard, self-image, self-efficacy, career commitment and job satisfaction, and legal illiteracy are some of the problems of women themselves (Bandura, 1977; Erickson, 1958, Schuler, 2010).

There also seems to be an implicit assumption on the part of women themselves that problems of equity for women have been entirely solved and there are no issues left to address (Coleman, 2009).

According to (Kann, 2009; Charlton, 2010), "women choose from a narrow range of occupations (that are low in status) and up in poorly paid jobs" and he adds to say that even when they are given equal opportunities to learn and get the necessary professional qualifications, they tend not to reach the higher levels of the professions probably because of the effect of sex role stereotypic attitudes of the society which might have deterred them from seeking high ranked positions.

Every society has its own stereotypic behavior patterns where the males and females are expected to follow (Whitmarsh, 2007). They begin to influence the behavioral and personality developments of individuals from early years of life. For example, Charlton (2010) theorized that individuals start developing personality traits of trust or mistrust in the first two years after birth. Thus, he said children view the world as safe, reliable, nurturing, and predictable if their parents encouraged them to develop a sense of trust by meeting their needs and providing them comfort ; or they view the world as full of threat, insecurity, uncertainty, and unreliable if their parents failed to meet their needs and were negligent to them. So, this phenomenon in the early years will leave an indelible scar on later developmental patterns. Within the next few years children will develop a sense of autonomy and independence if proper treatments and opportunities are offered to them by parents. The role of parents is kernel of the children's personality, behavior as well as cognitive developmental patterns (Bourdeau, Sennott \&Wilson, 2009).

According to Whitmarsh and Wentworth (2009), women choose the female dominated careers like teaching, exercise their choice based on early developmental experiences and also they are highly influenced by their mother or a female adult in their family who is in the same field that they choose. Hence, the issue of gender stereotyping starts to influence career aspirations at an early stage of human development. During the early stages of development young children view all occupations positively but while they are growing, they start developing their own preferences that are based on the compatibility of those occupations with their developing selfconcept (Charlton, 2010; Gottfredson, 2008).

Similarly, Derlega and Janda(1986) said that in the first few years of life individuals begin to label themselves as males or females. When children reach pre-school year (on the average 3 $1 / 2$ years) they evince strong preferences to gender stereotyped activities. As a consequence, male and female children start to assume different responsibilities and play varied roles at early years of age. 
The ways male and female children are treated and brought up in the family constellation, and the labels they receive from the society, only because they are males and females color their conceptions and perceptions of themselves. Accordingly, Frieze et al.,(1978) showed that men tend to overestimate their abilities while women tend to underestimate their abilities, although both may be equal in their abilities.

Furthermore, Dembo (1995) discusses that women have not entirely freed themselves from the effects of societal gender role stereotypes. He indicated that female and male children are still treated differently in the socialization processes as well as in ways of interaction in their families and the society at large. Accordingly, "girls ... are trained in to dependency, while boys are trained out of it.

Another serious problem is that of the queen bee syndrome-that is few females who are in a higher position of leadership are not willing to empower other women (Harankhedkar, 2011). Recent researches show that although significant steps have been made towards gender equality, in most modern work places including education, however, on average, women are still paid less than and achieve fewer promotions than their male counterparts. This queen bee syndrome maybe a product of the certain cultural influences, especially those related to work places. This queen bee syndrome may be developed by women who have achieved high work place positions within their respective fields as a way to defend against any gender bias found in their culture. By opposing any attempt of subordinates of their own sex to advance in career paths, women with queen bee syndrome hope to fit in with their male counterparts by adhering to the cultural stigmas placed on gender in the work place. Belittling female subordinates allows "queen bees" the opportunities to show more masculine qualities which they see as more culturally valuable and professional. By showing this supposedly important masculine qualities, queen bees seek to further legitimize their rights to be in important professional positions as well as attaining job security by showing commitment to their professional roles. Preventing the advancement of women below her is one way for a queen bee to reduce the number of competitors for resources and positions like promotion opportunities formally reserved or informally designated for allocation to women at and above her level, thereby easing her own progress up her career ladder.

On the other hand, Harankhedkar (2011), adds that "people with the queen bee syndrome are always there at the work place and it concerns women (queens) The woman shows the alpha male characteristics-dominant, ambitious, result-oriented, and somewhat insecure about people threatening her progress. In this regard, healthy competition at the work place is a very good sign, but indulging in pulling someone down to achieve what you want is worst (Harankhedkar, 2011).

Another self-related problem is the career-orientation and preferences of profession. Every individual is responsible for making choices that will enable him/her to actualize their career potential (Cook, Heppner \& O'Brien, 2009). However, women's career choices are affected by some additional factors such as the attitude of the institutions towards women, job prospects, family background, and career aspirations. In this regard, from early childhood and throughout their life, many women are exposed to pervasive messages that women's life should revolve around taking care of other people and that their career plans are somehow superimposed on this primary obligation (Cook et al., 2009). Chiloane-Tsoka (2010) adds to this in saying "sociocultural perceptions and societal values play an important role in women's attitudes towards certain occupations and can discourage women from pursuing leadership opportunities. 
Again, according to Gillem, Sehgal and Forcet (2009), women are seen as more interpersonally sensitive, warm and expressive than men and men are viewed as more competent, independent, objective and logical than women. These kinds of societal constructions that inform the notions of women as being less competent may lead to low self-image and less confidence(self-efficacy) in their own abilities (Gillem et al., 2009).

\section{Economic Barriers}

For centuries women were not treated equal to men in many ways. They were not allowed to own property, they did not have a share in the property of their parents, they had no voting rights, had no freedom to choose their work or job and so on. Now that they have come out of those dark days of oppression of women there is a need for strong movement to fight for the rights of women and to ensure that they get all the rights which men have or in other words a movement for the Empowerment of Women (WEF, 2012).

In most of the world women spend more hours per week than men do. However, for women, a larger proportion of time spent working is devoted to unpaid work-house chore, child care, and other domestic activities that are not counted when economists try to quantify work (UN, 2012), and yet accordingly, women continue to face unique constraints on their economic activities, constraints that are largely related to their roles and responsibilities in the household (WB, 2010). For this Otunga and Ojwang (2009), gave a stress on the issue and said that it didn't matter whether a woman is professional or not, she had to perform the woman's role in the home.

In expressing the role of women and undervaluation of their contribution, William (2008) restated the statistical quotation of the UN as:

Women perform $2 / 3$ of the world's work;

Women earn $1 / 10$ of the world's income;

Women are 2/3 of the world's illiterate;

Women own less than 1/100 of the world property.

Similarly, according to (Eagly \& Carli, 2010;WB, 2010), there are several economic factors affecting women's participation in education and educational leadership like poverty, limited access, and inadequate infrastructure, limited income generation, limited opportunities and inadequate supportive economic policy environment. Another important factor is the marriage between the economic and social un-equals-lack of companionate marriage.

\section{Political-Legal barriers}

According to Schuler (2010), in most societies laws and the applications are skewed against women. Women's subordination, based on unequal gender relations, is manifest in the law in several key areas, particularly labor law, penal law, and civil law, which governs legal capacity, rights and obligations in marriage, guardianship, inheritance, income, land rights and participation in public affairs. In some instances, women's inferior status results from formal legislation, but also it can result from prejudicial social practices not challenged by the law.

Another major problem with the law is that the vast majority of women are "outside the system" especially rural and urban poor women. Most women on the face of the earth do not think of themselves as having rights. They are outside the system because they do not know what the law offers them, but partly because the system doesn't offer them very much (Schuler, 2010). 
In most cases in Africa, women lack knowledge about both their rights and responsibilities--legal illiteracy. Key to this view is that when women know the law-their rights and obligations, they will be more functional citizens. However, in most societies the law and its application are skewed against women.

Again, according to Chandan (2009), both men and women can be successful leaders if they possess the required ability of inspiring others, problem solving skills, emotional maturity, understanding human behavior, verbal assertiveness, willingness to take risks, dedication to organizational goals, and skills like human relations skill, will, power, flexibility, sociability, intelligence, self-confidence, judgment, appearance, energy, drive, enthusiasm, appearance etc. However, according to the same author, because of different barriers, women lack some or many of them (Schuler, 2010).

On the other hand, the law enforcing agents like the police and the court lack knowledge regarding women rights, and are negative and ineffective in enforcing the law regarding women, and even where the laws are powerful and responsive , cultural, psychological, and political constraints hinder women from enjoyment of their rights. Social structures do not encourage or sometimes even permit women to act independently in their own interest (Schuler, 2010).

\section{Institutional Barriers}

One of the responsibilities of leadership is to seek out and develop the latent talent of those members who, for various reasons, have never had a real chance to demonstrate their ability (Clem, 2009). However, institutions and those who are in charge of running them are not aware of the different talents that different groups and sexes may have (Rotary International, 2011).

Lack of leader breeder is also another problem for the lack of women leaders in senior leadership position. Leader breeders are leaders who recruit high potentials, even if they are hard to handle. They do not go for the safe, conventional hires. And also lack of mentors who are also leader breeders is another reason for lack of women in leadership positions in education institutions (Gandz, 2007). According to this author, a leader breeder, unlike the leader blocker, has the emotional intelligence and uncanny sense required to attract, develop, and retain talent, regardless of their academic background. Such leaders also treat the failure of their subordinates as success, and give timely feedback and reward and reinforce the success of their followers (Gandz, 2007).

On the other hand, lack of effective training on the part of leaders who held the leadership position to play the role of mentor is another problem for lack of women leaders in education sector (Msila, 2012).

Lack of networking, mentoring, coaching, sponsorship, up-skilling and informing leaders and managers about the value of diversity and inclusion of women leaders, lack of training for future leaders and failure to respond to the needs of a diverse staff and students are other institutional barriers (Norma, 2013).

For educators who aspire to leadership positions or currently obtain positions as educational leaders, mentors are critical for job effectiveness (Coleman, 2010; de Santa Ana, 2008). Effective mentor relationships that incorporate a gender match are functional and can provide support for personal experiences with gender barriers. However, according to the above writers, many African educational institutions have no such a trend. 
Again, as CODESRIA (2009), the structure of many African educational institutions remain deliberately masculine, in terms of their representational structure, decision making procedures and the culture of their members. Women continue to be minorities in higher education and those involved in these institutions are fragmented and isolated for various social, economic, cultural and psychological reasons.

Another problem of gender at institutions also attribute to lack of strategies that bring about reorganization and transformation of African Education Institutions in a permanent way that opens up opportunities for career development and career advancement for women while recognizing their multiple gender specific roles(Amina, 2009).

Shakeshaft (1989) and Cubillo and Brown (2003) mention that the chief source of male hegemony lies not only in the psychological make- up of individuals but in the structure and operation of organizations like universities where women behave in the self- limiting ways not only because they were socialized as females, but because of their presence in lower power positions, low visibility, and boring jobs (Chiloane-Tsoka, 2010). Similarly, Cubillo and Brown (2003), describes the situation of women as the "outsiders inside", i.e. inside the institution but outside the "boys' club". As mentioned by women's affairs department, MOE (2010), for example, higher education institutions tend to have organizational culture that does not allow for diversity, which in turn resulted in scarcity of women in leadership position of educational institutions. Therefore, the hiring body too, considers women as less experienced or less prepared for leadership than men. According to (Acker, 2003; Singh, 2002, 2008), institutions like universities are patriarchal institutions that inevitably put women in the lower positions and inevitably favor men. And such institutions lack transparency and accountability in hiring and promoting (Camen, 2010).

Another serious problem for the underrepresentation of women is that of the implicit male violence over females.

Some scholars have argued that the major problem in academia is power, rather than gender per se, and that what is needed to solve the gender problem is to actualize the democratization of the institution (Ronning, 2009). This is related with inequality-inequality in academia cannot be gender-free.

Again, another important institutional problem is that most African educational institutions have no sensitive and functioning gender institutes within them that exhaustively understand the existing problems, conduct research, and come up with solutions or findings to promote women leadership in higher positions-encouraged to address transformative strategies linked to research, curriculum design, management and decision making(CODESRIA, 2009)who thinks of and challenges the ways of deconstructing the complex existing dynamics of injustice and inequalities in higher education while taking cognizance of the challenging environment.

Furthermore, according to (Bush, 2010; CODESRIA, 2009), women's access to power has been observed to be limited because of their low level of education. In other words, the pool of potential women leaders is small. Disparity is noticed in the pattern of students' enrollment in various universities (Onsongo, 2009; Odhiambo,2011). The ratio of men to women on enrollment confirms the fact that lukewarm attitude towards females' education is a common phenomenon. The percentage of female in academic sector is still low. Hence, females are still marginalized, subjugated and discriminated against in the area of decision making, the economy, politics, employment and so on (WB, 2012). Education at all levels in Africa is 
gendered terrain and gender disparities are even more pronounced in education. Although some strides have been made in terms of the participation of women in African education as evidenced by increasing female student numbers and a significant number of females completing under graduate and graduate degrees, patriarchal knowledge is still coded into everyday practices is still relevant in the discourse on education sector. For example, fewer women compared to men proceed to establish careers and to occupy senior positions at African educational institutions (CODESRIA, 2009).

\section{Women Supportive Leadership Theories}

While many different leadership theories have emerged and the concept of some overlap with the other, however, the researcher is interested in the theories discussed below taking into account that they are relevant and support women leadership most in educational institutions(Cherry, 2014; Yukl, 2010).

\section{Democratic Leadership Theories}

Female leadership tends towards a style defined as "interactive leadership" that involves: encouraging, participation, sharing power and information, enhancing self-worth, changing self-interests for an overall good, relating power to interpersonal skill, and believing in better performance when feeling good. As Tsegaye (2013), women leaders value having influence more than having power (Trinidad \& Normore, 2005).Democratic leadership theories suggest that the ideal leadership style is one that takes the input of others into account. These leaders encourage the participation and contribution from group members and help group members feel more relevant and committed to decision making process (Bush, 2006).This leadership model assumes that the decision making processes of the group ought to be the central focus of the group (Leithwood, 2009; Bush, 2006; 2010). This model is underpinned by three assumptions: Participation will increase organizational effectiveness; Participation is justified by democratic principles; and in the context of site-based management, leadership is potentially available to any legitimate stakeholder (Leithwood, 2009).Sergiovanni (1999) also adds to this as "participative leadership bonds staff together and in easing the pressures on institutional leaders - the burdens of the leadership will be less if leadership functions and roles are shared and if the concept of leadership density were to emerge as a viable replacement for principal leadership". So, this theory fits to the leadership of women since they are known to apply democratic leadership style.

Research findings also show that women adopt democratic and participative leadership styles in the corporate world and in education

\section{Transformational Leadership}

Transformational leadership is the preferred leadership style used by women. The characteristics of transformational leadership relate to female values developed through socialization processes that include building relationships, communication, consensus building, power as influence, and working together for a common purpose(Trinidad \& Normore, 2005; Tsegay, 2013). These authors argue further that the effectiveness of leadership, among other things, is characterized by the ability to motivate people, build relationships and influence outcomes. The behavior that is modeled by the leader and the top management profoundly shape and thereby determine competency level of their juniors. A transformational leader has a major impact on the quality and efficiency level of subordinates ( Kouzes \& Posner, 2010). It is characterized as inspirational leadership, intellectual stimulation, individualized consideration, and charisma (Kouzes \& Posner, 2010). These theories focus on the connections formed between leaders and followers. Transformational leaders motivate and inspire people by helping the group members see the importance and higher good of the task. These leaders 
focus on the performance of group members, but also want each person to fulfill his or her potential. Such leaders often have high ethical and moral standards (Hilaire, 2009; Lumby, 2017). This theory advances the idea that an effective leader is discernible by his or her actions (Hilaire, 2009). After an analysis of the list of behaviors at Ohio and Michigan state universities, scholars presented two categories-consideration that is when leaders are concerned about their subordinates as people, are trusted by their subordinates, are progressive to them, and promote camaraderie(friendship). On the other hand, initiating structure refers to a style in which the leader defines closely and clearly what subordinates are supposed to do and how, and actively schedules work for them (Hilaire, 2009;Avolio et al., 2009).Transformational leadership allows a woman leader to be warm and communal(Eagly \& Carli, 2007).

Transformational leaders build relationships with followers through interactive communication, which forms a cultural bond between the two participants and leads to a shifting of values by both parties toward common ground. He/she inspires followers to see the attractive future possibilities and communicates expectations, and demonstrates a commitment to goals and shared vision. According to Fernandez (2010), an intellectually stimulating leader arouses in others a greater cognizance of problems, awareness of their own thoughts and imagination, and recognition of their beliefs and values. Again, transformational leaders recognize and satisfy their immediate associates' current needs and expand and elevate them so that they reach their full potential. He/she makes his/her companions feel empowered enough to organize their own initiatives. They effect change in others using a variety of methods including defining or redefining the cultures of the organization as well as working together closely with associates.

Bush (2004) links three leadership models to his collegial management model, out of which the first is transformational leadership. This form of leadership assumes that the central focus of leadership ought to be the commitments and capacities of organizational members. Higher levels of personal commitment to organizational goals and greater capacities for accomplishing those goals are assumed to result in extra effort and greater productivity (Leithwood, 2009; Posner, 2010). According to him, this transformational leadership is conceptualized along eight dimensions: building organizational vision, establishing organizational goals, providing intellectual stimulation, offering individualized support, modeling best practices and important organizational values, demonstrating high performance expectations, creating a productive organizational culture, and developing structures to foster participation in organizational decisions.

According to (Caldwell and Spinks, 1992; Hilaire, 2010), transformational leaders succeed in gaining the commitment of others to such a degree that higher levels of accomplishment become virtually a moral imperative. In this regard, women are highly qualified for listening to others which is one of the characteristics of transformational leaders (Dereje, 2009). So, this theory is also likely to be applicable by women.

It is a leadership strategy that generates reform in the stakeholders, school culture, and educational organizations (Burton \& Peachey, 2009). It improves the teachers' performance and students' achievement (Chegini, 2010). According to Abu-Tineh et al. (2009) transformational leaders achieve extraordinary results by developing a shared vision, setting the example, challenging the status quo, and supporting the staff. Transformational leadership is considered a moral endeavor that raised the morale and motivation of the leader and followers to a higher level (Pepper, 2010). Transformational leaders are described as exhibiting inspirational motivation, intellectual stimulation, idealized influence, and individual consideration (Kouzes \& Posner, 2007; Hoy \& Miskel, 2008). The transformational leadership 
practices allow the leaders to achieve the goals set by the organization and obtain exceptional results (Kouzes \& Posner, 2007).

\section{Relational Leadership Theory}

This is a theory developed by Regan and Brooks in1995 (Smit, 2014). They developed this theory based on the resistance to the already existing socialization of women into the prevailing male-dominant culture. An emerging trend in female leadership theories is the relational perspective and approach (Cathcart, 2014; Fairhurst \&Uhl -Bien, 2012; Uhl Bien, 2006, 2007, 2011). It argues that females value relationships with colleagues more than males. Shake shaft (2006) also adds to this saying that more value of women result in their good communication with others, team-work, collaboration and community connection. According to Smit (2014) also women resisted the previously male traditional administrative behavior that is modeled by their male counterparts. It is opposite to that of the male controlling behavior (Smit, 2014). Leadership as relational influence can be performed by anyone, it is not a person or a place or a thing, instead, it is a verb: "leadership is the action of influence; it is relation and it doesn't exist by itself"(Smit, 2014). This leadership theory or concept is concerned about the concepts like care, vision, collaboration, courage and intuition, which are seen to be feminist attributes of leadership. While these concepts are not new in literature, however, they are given new conceptualizations for the practice of relational leadership (Smit, 2013; Genet, 2014).

Attributes of relational leadership differ greatly from the traditional administrative language of control, hierarchy, authority, and division of labor. Whilst traditional and relational languages are at opposite ends, it does not mean that relational language is only meant to female leaders. Instead, it is meant for all genders (Smit, 2013; Meaza, 2009). Accordingly, what is enlightening here is that the increased presence of women leaders, as well as the emerging feminist scholarship in this field, is corollary to the widening acceptance of the idea of leadership as relational (Smit, 2013). Here, out of the many definitions of relational leadership, for this study, that of the Uhl-Bien's definition of 2006 G.C is used. According to this author, relational leadership is a "social influence process through which emergent co-ordination (that is, evolving social order)and change(for example, new values, attitudes, approaches, behaviors and ideologies) are constructed and produced. This definition locates leadership in a jointly constructed but disembodied process, not in individuals. Uhl-Bien (2006) proposes this relational leadership theory as an approach that can encompass both individuated and connected perspectives by explaining both the emergence of leadership relationships(drawing on traditional individuated views that focus on the nature of the relationship, such as the leader-member exchange), and the relational dynamics of organizing which includes various constructionist views of leadership. it is also suggested as it is about being in relationships with others in a horizontal rather than a hierarchical sense(Grogan \& Shake shaft, 2011). Relations produce power in a flattened organizational structure. Leaders who develop coherence around shared values are likely to deepen the sense of community with an organization-a sense of being in relationship with others who are striving for the same goal (Grogan \& Shake shaft, 2011; Smit, 2013). Achieving goals usually takes place with and through others; power is conceptualized differently emphasizing that power of everyone should be expanded. Given the male dominance of males, women often would express their discomfort with power and deny their own power. What is changed is the language in use of power-power with rather than power over (Grogan \& Shake shaft, 2011).

\section{Instructional Leadership}

This focuses on the direction of influence, rather than its nature and source. This refers to the increasing emphasis on managing teaching and learning as the core activities of educational 
institutions. According to (Southworth, 2008; Bush, 2009; Sergiovanni, 2009), instructional leadership is strongly concerned with teaching and learning, including the professional learning of teachers as well as student growth. In this regard, women embrace relationships, sharing and process. Women educational administrators focus on instructional leadership in supervisory practice and they are concerned with students' individual differences, knowledge of curriculum teaching, methods, and the objective of teaching (Conner, 1992, 2012). In the area of instructional leadership, women spend more years as principals and teachers, and have more degrees than men; they emphasize the importance of curriculum and instruction in their work (Tallerico \&Burstyn,1996), while men emphasize more the organizational matters (Conner, 1992,2011). Women interact more with teachers, students, parents, colleagues, community etc. And they support contributive, consensual decision making, and emphasize the process. Women also encourage feelings of self -worth, active participation, and sharing of power and information, which helps to transform people's self- interest into organizational goals. They influence teachers to use more desirable teaching methods, emphasize the importance of curriculum and instruction more (Getskow, 2007; Eakle, 2013; Ryder, 1994; Porat, 2012).

Women lean toward facilitative leadership, enabling others to make their contributions through delegations, encouragement, and nudging from behind (Porat, 2010). This is because, women's main focus is on relationships, and they interact more frequently than men with teachers, students, parents, non-parent community members, professional colleagues, and supper ordinates (Conner, 2011).Furthermore, women are more interested in transforming people's self- interest into organizational goals by encouraging feelings of self- worth, active participation, and sharing of power and information (Getskow, 2007). And women spend more time in unscheduled meetings, visible on school campus, and observing teachers considerably more than male principals (Ryder, 2015). Moreover, women principals are more likely to interact with their staff and spend more time in the class room or with teachers discussing the academic and curricular areas of the instruction, and they are more likely to influence teachers or instructors to use more desirable teaching methods (Bush, 2010).So, in this regard, instructional leadership is thought to be supportive to women leadership of higher education institutions.

\section{Research Method}

\section{RESEARCH DESIGN AND METHODOLOGY}

The research method used for this study was a mixed method with concurrent approach.

\section{Research Design}

Descriptive survey was employed as a research design based on the nature of the problem and the importance of it.

\section{Population, sample size and sampling Techniques}

According to Morrison, Manion, and Cohen (2007), population refers to set of the people to whom the inquiry is addressed. Relying on only one source is not enough to develop an indepth understanding (Creswell, 2012; Patton, 2009). Taking this reality into account, the study employed many sources of data. Accordingly, the target population of this study was teachers of secondary schools, principals of secondary schools, supervisors of secondary schools, and heads of the education offices of Dawro and Wolaita administrative zones of southern Nations, Nationalities, and Peoples regional state. 200 teachers were selected by simple random sampling technique; 10 principals, 10 supervisors, and 8 heads of education offices were selected using purposive sampling techniques based on their long experiences. 


\section{Sources of Data}

Both primary and secondary sources of data were employed. The primary sources were teachers of the secondary schools(grades 9-12), supervisors of secondary schools, and heads of secondary schools, and heads of district education offices of Dawro and Wolaita administrative zones of southern Ethiopia. The secondary sources were the statistics of women teachers and leaders in the education sector of the two zones since 2017.

\section{Data Administration}

Pilot study with one secondary school that was not part of the study was used to pilot testing. 20 close-ended questionnaires were designed and distributed among 10 individual teachers of the aforementioned school, and returned $100 \%$. Then, it was checked for its reliability and validity using Cronbach alpha. The result showed that 0.85 or $85 \%$ of it was reliable. Then, based on this, actual data collection tools were prepared and time to collect data was arranged with the participants of the study, tools distributed, and returned $100 \%$.

\section{Data Collection Tools}

Close-ended questionnaire with 3 and 5 likert--scale, open-ended questionnaire, focus group discussions, and documents were used to collect data.

\section{Data Analysis Tools}

Frequency counts and percentages were employed to analyze data. Quantitative data were analyzed through frequency counts and Percentage. The qualitative data obtained through unstructured interviews and open-ended questionnaire were narrated and used as supportive for the quantitative ones.

\section{Dependent Variables}

\section{VARIABLES}

Dependent variable was the high participation of women in the leadership positions of schools, clusters, district education offices, and zonal education department positions of Dawro and Wolaita administrative zones of the southern regional state of Ethiopia.

\section{Independent Variables}

All the factors that affected the participation of women in leadership and management positions of the education sector of the two zones were independent variables. These were women's self- related factors, economic factors, political legal factors, socio-cultural and institutional factors. 


\section{DISCUSSIONS AND THE FINDINGS}

Table 1: Women Self- related Factors by Teachers

Key: 3=High; 2=Medium; 1=Low

\begin{tabular}{|c|l|c|c|c|c|c|c|}
\hline \multirow{2}{*}{ S.N. } & \multicolumn{1}{|c|}{ Items } & \multicolumn{5}{|c|}{$\begin{array}{c}\text { N=200 } \\
\text { Rating Scales }\end{array}$} \\
\cline { 3 - 8 } & & \multicolumn{2}{|c|}{3} & \multicolumn{2}{|c|}{2} & \multicolumn{2}{c|}{1} \\
\hline 1 & Access to education & 35 & $17.5 \%$ & 110 & $55 \%$ & 55 & $27.5 \%$ \\
\hline 2 & Experience & 45 & $22.5 \%$ & 35 & $17.5 \%$ & 120 & $60 \%$ \\
\hline 3 & $\begin{array}{l}\text { Self-confidence /self- } \\
\text { efficacy }\end{array}$ & 17 & $8.5 \%$ & 48 & $24 \%$ & 135 & $67.5 \%$ \\
\hline 4 & Self esteem & 36 & $18 \%$ & 40 & $20 \%$ & 124 & $62 \%$ \\
\hline 5 & $\begin{array}{l}\text { Love for leadership } \\
\text { profession }\end{array}$ & 40 & $20 \%$ & 50 & $25 \%$ & 110 & $55 \%$ \\
\hline 6 & $\begin{array}{l}\text { Pool of educated } \\
\text { women }\end{array}$ & 40 & $20 \%$ & 102 & $51 \%$ & 58 & $29 \%$ \\
\hline 7 & workload & 154 & $77 \%$ & 30 & $15 \%$ & 16 & $8 \%$ \\
\hline 8 & $\begin{array}{l}\text { Qualification of } \\
\text { women }\end{array}$ & 44 & $22 \%$ & 55 & $27.5 \%$ & 101 & $50.5 \%$ \\
\hline 9 & Specialization & 17 & $8.5 \%$ & 46 & $23 \%$ & 137 & $68.5 \%$ \\
\hline 10 & Networking interest & 10 & $5 \%$ & 25 & $12.5 \%$ & 165 & $82.5 \%$ \\
\hline 11 & $\begin{array}{l}\text { Competence on } \\
\text { leadership }\end{array}$ & 32 & $16 \%$ & 10 & $5 \%$ & 158 & $79 \%$ \\
\hline 12 & $\begin{array}{l}\text { Commitment to } \\
\text { leadership }\end{array}$ & 17 & $8.5 \%$ & 109 & $54.5 \%$ & 74 & $37 \%$ \\
\hline 13 & Legal literacy & 30 & $15 \%$ & 27 & $13.5 \%$ & 143 & $71.5 \%$ \\
\hline 14 & $\begin{array}{l}\text { Queen bee syndrome } \\
\end{array}$ & 161 & $80.5 \%$ & 32 & $16 \%$ & 7 & $3.5 \%$ \\
\hline 15 & Level of socialization & 139 & $69.5 \%$ & 40 & $20 \%$ & 21 & $10.5 \%$ \\
\hline 16 & $\begin{array}{l}\text { Attitude towards } \\
\text { their talent }\end{array}$ & 45 & $22.5 \%$ & 54 & $27 \%$ & 101 & $50.5 \%$ \\
\hline & & & & & & \\
\hline
\end{tabular}

Access for girls or women to education was medium or moderate according to $110(55 \%)$ of respondents (item 1). According to women's experience to leadership, as to $120(60 \%)$ of respondents, they had less experience. According to item 3, women had low self-confidence and self-efficacy as to $135(67.5 \%)$ respondents, and also low self-esteem according to $124(62 \%)$ of respondents (item 4). As to 110 (55\%) of respondents-item 5, women had low love or interest for the leadership profession in education. According to item 7-154(77\%) of the respondents responded that women were overburdened by work. Item 8 also showed that women were less qualified according to 101(50.5\%) of respondents, and also had low specialization in the area of educational leadership (item 9). Regarding item 10, women were found to have low interest in networking with each other according to 165(82.5\%) of respondents. With regard to item 11, according to $158(79 \%)$ of respondents, women had low competence for educational leadership, and also according to item 12, women were found to be moderately committed to leadership according to $109(54.5 \%)$ of respondents. Women were found to be legally illiterate according to $143(71.5 \%)$ of respondents-item 13 . According to $161(80.5 \%)$ respondents, women who had already assumed leadership positions were found to be against towards other aspiring women leaders-item 14. With regard to item 15, level of socialization of women towards negative attitudes of society was high according to $139(69.5 \%)$ of respondents. Again, with regard to item 16, according to 101(50.5\%) of respondents, attitudes of women towards their talents was found to be low. Data obtained through interviews and open-ended questionnaires too, supported this finding. 
Table 2: Socio-cultural factors by Teachers

Key: 3=High; 2=Medium; 1=Low

\begin{tabular}{|c|l|c|c|c|c|c|c|}
\hline \multirow{2}{*}{ S. No. } & \multicolumn{1}{|c|}{ Items } & \multicolumn{6}{|c|}{$\begin{array}{c}\text { N=200 } \\
\text { Rating scales }\end{array}$} \\
\cline { 2 - 8 } & & \multicolumn{2}{|c|}{3} & \multicolumn{2}{|c|}{2} & \multicolumn{2}{c|}{1} \\
\hline 1 & $\begin{array}{l}\text { Sex- } \\
\text { stereotype }\end{array}$ & 123 & $61.5 \%$ & 50 & $25 \%$ & 27 & $13.5 \%$ \\
\hline 2 & Glass ceiling & 111 & $55.5 \%$ & 49 & $24.5 \%$ & 40 & 20 \\
\hline 3 & $\begin{array}{l}\text { House } \\
\text { chores }\end{array}$ & 157 & $78.5 \%$ & 26 & $13 \%$ & 17 & $8.5 \%$ \\
\hline 4 & $\begin{array}{l}\text { Early } \\
\text { marriage }\end{array}$ & 33 & $16.5 \%$ & 22 & $11 \%$ & 145 & $72.5 \%$ \\
\hline 5 & $\begin{array}{l}\text { Physical } \\
\text { fitness }\end{array}$ & 7 & $3.5 \%$ & 123 & $61.5 \%$ & 70 & $35 \%$ \\
\hline 6 & $\begin{array}{l}\text { Use of } \\
\text { proverbs } \\
\text { that reflect } \\
\text { negative } \\
\text { attitude }\end{array}$ & 99 & $49.5 \%$ & 50 & $25 \%$ & 51 & $25.5 \%$ \\
\hline
\end{tabular}

According to item 1, as to $123(61.5 \%)$ of respondents, sex stereotype was still high in the Dawro and Wolaita administrative zones. Again the prevalence of glass ceiling was high according to $111(55.5 \%)$ of respondents. Women were still over burdened with house chores, according to $157(78.5 \%)$ of respondents(item 3). Physical fitness and early marriage were not such serious problems in the two administrative zones. On the other hand, the negative expressions and proverbs that discourage women were still highly prevalent according to 99(49.5\%)of respondents. Data obtained through interviews and open-ended questionnaires too, supported this finding.

Table 3: Political--Legal factors

Key: 3=High; 2=Medium;1=Low

\begin{tabular}{|c|l|c|c|c|c|c|c|}
\hline \multirow{2}{*}{ S.No. } & \multicolumn{5}{|c|}{ Items } & \multicolumn{5}{c|}{$\begin{array}{c}\text { N=200 } \\
\text { Rating Scales }\end{array}$} \\
\cline { 3 - 8 } & & \multicolumn{2}{|c|}{3} & \multicolumn{2}{c|}{2} & \multicolumn{2}{c|}{1} \\
\hline 1 & $\begin{array}{l}\text { Presence of affirmative } \\
\text { action }\end{array}$ & 120 & $60 \%$ & 65 & $32.5 \%$ & 15 & $7.5 \%$ \\
\hline 2 & $\begin{array}{l}\text { Level of policy } \\
\text { implementation/mismatch } \\
\text { between policy and action }\end{array}$ & 130 & $65 \%$ & 30 & $15 \%$ & 40 & $20 \%$ \\
\hline 3 & Level of advocacy & 120 & $60 \%$ & 34 & $17 \%$ & 46 & $23 \%$ \\
\hline 4 & Legal support & 34 & $17 \%$ & 43 & $21.5 \%$ & 123 & $61.5 \%$ \\
\hline 5 & $\begin{array}{l}\text { Legal framework to } \\
\text { empower women } \\
\text { economically }\end{array}$ & 102 & $51 \%$ & 65 & $32.5 \%$ & 33 & $16.5 \%$ \\
\hline 6 & Access to schools & 134 & $67 \%$ & 60 & $30 \%$ & 6 & $3 \%$ \\
\hline
\end{tabular}

Though there was affirmative action in the country, however, there was a mismatch between the level of implementation of affirmative action and the policy according to $120(60 \%)$ and $130(65 \%)$ of respondents according to items 1 and 2 . With regard to item 4 , according to $123(61.5 \%)$ of respondents, the legal support made for women was low, there was high advocacy level according to $120(60 \%)$ of respondents. With regard to items 5 and 6, frame work to empower women and access to schools were high though there were problems in 
implementation. Data obtained through interviews and open-ended questionnaires too, supported this finding.

Table 4: Economic factors

Key: 3=High; 2=Medium;1=Low

\begin{tabular}{|c|l|c|c|c|c|c|c|}
\hline \multirow{2}{*}{ S..No. } & \multirow{2}{*}{ Items } & \multicolumn{5}{|c|}{$\begin{array}{c}\text { N=200 } \\
\text { Rating scale }\end{array}$} \\
\cline { 3 - 8 } & & \multicolumn{2}{|c|}{3} & \multicolumn{2}{|c|}{2} & \multicolumn{2}{c|}{1} \\
\hline 1 & $\begin{array}{l}\text { Family economic } \\
\text { background }\end{array}$ & 8 & $4 \%$ & 65 & $32.5 \%$ & 127 & $63.5 \%$ \\
\hline 2 & $\begin{array}{l}\text { Means of economic } \\
\text { resources }\end{array}$ & 19 & $9.5 \%$ & 70 & $35 \%$ & 111 & $55.5 \%$ \\
\hline 3 & Labour law & 60 & $30 \%$ & 85 & $42.5 \%$ & 55 & $27.5 \%$ \\
\hline 4 & Access to schools & 155 & $77.5 \%$ & 30 & $15 \%$ & 15 & $7.5 \%$ \\
\hline 5 & Infrastructure & 28 & $14 \%$ & 65 & $32.5 \%$ & 107 & $53.5 \%$ \\
\hline 6 & $\begin{array}{l}\text { Payment made for } \\
\text { women employees } \\
\text { at low levels }\end{array}$ & 35 & $17.5 \%$ & 53 & $26.5 \%$ & 112 & $56 \%$ \\
\hline
\end{tabular}

Items 1and 2 showed that women had low or poor economic background and economic resources according to $127(63.5 \%)$ and $111(55.5 \%)$ respondents respectively. There were also poor infrastructure and low payment according to 107(53.5\%) and 112(56\%) of respondents respectively according to items 5 and 6. Data obtained through interviews and open-ended questionnaires too, supported this finding. 
Table 5: Institutional factors

Key: 3=High; 2= Medium; 1=Low

\begin{tabular}{|c|c|c|c|c|c|c|c|}
\hline \multirow[t]{2}{*}{ S. .No } & \multirow[t]{2}{*}{ Items } & \multicolumn{6}{|c|}{$\begin{array}{l}\mathrm{N}=200 \\
\text { Rating scale }\end{array}$} \\
\hline & & \multicolumn{2}{|l|}{3} & \multicolumn{2}{|l|}{2} & \multicolumn{2}{|l|}{1} \\
\hline 1 & $\begin{array}{l}\text { Interest to } \\
\text { advance women }\end{array}$ & 15 & $7.5 \%$ & 21 & $10.5 \%$ & 164 & $82 \%$ \\
\hline 2 & Male violence & 136 & $68 \%$ & 54 & $27 \%$ & 10 & $5 \%$ \\
\hline 3 & Work load & 124 & $62 \%$ & 34 & $17 \%$ & 42 & $21 \%$ \\
\hline 4 & $\begin{array}{l}\text { Plan of women } \\
\text { leader } \\
\text { development }\end{array}$ & 35 & $17.5 \%$ & 45 & $22.5 \%$ & 120 & $60 \%$ \\
\hline 5 & $\begin{array}{l}\text { Attention for } \\
\text { organizing } \\
\text { Women forum }\end{array}$ & 25 & $12.5 \%$ & 56 & $28 \%$ & 119 & $59.5 \%$ \\
\hline 6 & $\begin{array}{l}\text { Facilities } \\
\text { provision }\end{array}$ & 9 & $4.5 \%$ & 45 & $22.5 \%$ & 146 & $73 \%$ \\
\hline 7 & $\begin{array}{l}\text { Transparent } \\
\text { recruitment } \\
\text { criteria }\end{array}$ & 35 & $17.5 \%$ & 43 & $21.5 \%$ & 122 & $61 \%$ \\
\hline 8 & $\begin{array}{l}\text { Transparent } \\
\text { promotion } \\
\text { criteria }\end{array}$ & 31 & $15.5 \%$ & 35 & $17.5 \%$ & 134 & $67 \%$ \\
\hline 9 & $\begin{array}{l}\text { Model women } \\
\text { leaders }\end{array}$ & 14 & $7 \%$ & 12 & $6 \%$ & 174 & $77 \%$ \\
\hline 10 & $\begin{array}{l}\text { Prevalence of } \\
\text { motivation for } \\
\text { aspiring women }\end{array}$ & 14 & $7 \%$ & 58 & $29 \%$ & 128 & $64 \%$ \\
\hline 11 & $\begin{array}{l}\text { Attractive } \\
\text { incentive }\end{array}$ & 32 & $16 \%$ & 68 & $34 \%$ & 100 & $50 \%$ \\
\hline 12 & Attractive salary & 37 & $18.5 \%$ & 36 & $18 \%$ & 127 & $63.5 \%$ \\
\hline 13 & $\begin{array}{l}\text { Strategy to } \\
\text { women } \\
\text { promotion }\end{array}$ & 30 & $15 \%$ & 51 & $25.5 \%$ & 119 & $59.5 \%$ \\
\hline 14 & $\begin{array}{l}\text { Attitude towards } \\
\text { complexity of } \\
\text { educational } \\
\text { leadership for } \\
\text { women }\end{array}$ & 126 & $63 \%$ & 32 & $16 \%$ & 42 & $21 \%$ \\
\hline 15 & $\begin{array}{l}\text { Denial for } \\
\text { advanced } \\
\text { leadership } \\
\text { training for } \\
\text { women }\end{array}$ & 135 & $67.5 \%$ & 25 & $12.5 \%$ & 40 & $20 \%$ \\
\hline 16 & $\begin{array}{l}\text { Holding } \\
\text { precarious } \\
\text { positions of } \\
\text { leadership by } \\
\text { women }\end{array}$ & 154 & $77 \%$ & 23 & $11.5 \%$ & 23 & $11.5 \%$ \\
\hline 17 & $\begin{array}{l}\text { Reward system } \\
\text { for aspiring } \\
\text { women leaders }\end{array}$ & 35 & $17.5 \%$ & 124 & $62 \%$ & 41 & $20.5 \%$ \\
\hline
\end{tabular}




\begin{tabular}{|c|c|c|c|c|c|c|c|}
\hline 18 & $\begin{array}{l}\text { Interest to breed } \\
\text { potential women } \\
\text { leaders }\end{array}$ & 7 & $3.5 \%$ & 54 & $27 \%$ & 139 & $69.5 \%$ \\
\hline 19 & $\begin{array}{l}\text { Awareness on the } \\
\text { part of top } \\
\text { leaders regarding } \\
\text { the leadership } \\
\text { talent of women }\end{array}$ & 14 & $7 \%$ & 22 & $11 \%$ & 164 & $82 \%$ \\
\hline 20 & $\begin{array}{l}\text { Work place } \\
\text { dynamics }\end{array}$ & 141 & $70.5 \%$ & 32 & $16 \%$ & 27 & $13.5 \%$ \\
\hline 21 & Glass-cliff & 99 & $49.5 \%$ & 46 & $23 \%$ & 55 & $27.5 \%$ \\
\hline 22 & $\begin{array}{l}\text { Prevalence of } \\
\text { mentors in } \\
\text { schools }\end{array}$ & 31 & $15.5 \%$ & 45 & $22.5 \%$ & 124 & $62 \%$ \\
\hline 23 & $\begin{array}{l}\text { Cooperation } \\
\text { among women } \\
\text { academic staff }\end{array}$ & 22 & $11 \%$ & 32 & $16 \%$ & 146 & $73 \%$ \\
\hline 24 & $\begin{array}{l}\text { Addressing } \\
\text { diversity of } \\
\text { gender in } \\
\text { educational } \\
\text { leadership }\end{array}$ & 24 & $12 \%$ & 37 & $18.5 \%$ & 139 & $69.5 \%$ \\
\hline
\end{tabular}

According to $164(82 \%)$ of respondents, educational institutions had no interest to empower women-item 1 above. Male violence and workload were high in educational institutions for women according to $136(68 \%)$ and $124(62 \%)$ of respondents respectively (items 2 and 3). There was poor plan for developing women potential and aspiring leaders by the concerned leaders. And also low attention was made to organize women forum according to $119(59.5 \%)$ of respondents-item 5. And also there was poor provision of facilities for aspiring women leaders according to 146 (73\%) of respondents. And also there were no transparent recruitment and promotion policy in schools, district education offices and clusters as well with regard to items 7 and 8. Again there were no model women leaders who could have encouraged the aspiring women for leadership according to item 9 above. There were low motivation mechanism, low incentives and low salary that could have retained and brought women to the leadership positions according to items 10,11, and 12 above. There was poor strategy for women leadership development, high negative attitude by others towards the competency level of women regarding leadership, and high denial for the advanced leadership training for women according to items 13,14 , and 15 . With regard to item 16, women highly held precarious positions of leadership. According to $139(69.5 \%)$ of respondents-item 18, the interest of institutions to breed the aspiring potential women leaders was low. Awareness on the part of top managers about the talent of women was found to be low according to $164(82 \%)$ of respondents-item 19 . There were glass cliff and work place dynamics, and low level of mentors for women in educational sectors including schools according to items 20, 21, and 22. Low co-operation among women academic staff and diversity of men and women in leadership were poorly addressed in educational sectors like schools, district education offices, and clusters as well in the two zones of Wolaita and Dawro administrative zones of south Ethiopia, according to items 23 and 24. Data obtained through interviews and open-ended questionnaires too, supported this finding. 
Table 6; Rating Variables (Items) in their rank of seriousness Key: $5=$ =very serious;4=serious; $3=$ =moderate;;2=less serious;;1=least serious

\begin{tabular}{|c|c|c|c|c|c|c|c|c|c|c|c|c|}
\hline \multirow[t]{2}{*}{ S.No. } & \multirow[t]{2}{*}{ Items } & \multicolumn{10}{|c|}{$\begin{array}{c}\mathrm{N}=200 \\
\text { Rating Scale }\end{array}$} & \multirow[t]{2}{*}{ Rank } \\
\hline & & \multicolumn{2}{|l|}{5} & \multicolumn{2}{|l|}{4} & \multicolumn{2}{|l|}{3} & \multicolumn{2}{|l|}{2} & \multicolumn{2}{|l|}{1} & \\
\hline 1 & $\begin{array}{l}\text { Women } \\
\text { self-related } \\
\text { problems }\end{array}$ & 159 & $79.5 \%$ & 15 & $7.5 \%$ & 11 & $5.5 \%$ & 9 & $4.5 \%$ & 6 & $3 \%$ & $2^{\text {nd }}$ \\
\hline 2 & $\begin{array}{l}\text { Socio- } \\
\text { cultural } \\
\text { problems }\end{array}$ & 134 & $67 \%$ & 27 & $13.5 \%$ & 20 & $10 \%$ & 10 & $5 \%$ & 9 & $4.5 \%$ & $3^{\text {rd }}$ \\
\hline 3 & $\begin{array}{l}\text { Institutional } \\
\text { problems }\end{array}$ & 165 & $82.5 \%$ & 18 & $9 \%$ & 7 & $3.5 \%$ & 4 & $2 \%$ & 5 & $2.5 \%$ & $1^{\text {st }}$ \\
\hline 4 & $\begin{array}{l}\text { Political- } \\
\text { legal } \\
\text { problems }\end{array}$ & 112 & $56 \%$ & 43 & $21.5 \%$ & 34 & $17 \%$ & 6 & $3 \%$ & 5 & $2.5 \%$ & $5^{\text {th }}$ \\
\hline 5 & $\begin{array}{l}\text { Economic } \\
\text { problems }\end{array}$ & 123 & $61.5 \%$ & 45 & $22.5 \%$ & 21 & $10.5 \%$ & 10 & $5 \%$ & 1 & $0.5 \%$ & $4^{\text {th }}$ \\
\hline
\end{tabular}

The table above showed that all the items or variables were serious problems since all of them were more than $50 \%$ serious. Institutional problems were ranked first in the order of seriousness compared with other variables according to $165(82.5 \%)$ of respondents. Women's self-related problems stood second according to $159(79.5 \%)$ respondents. Socio-cultural factors stood third compared with other variables. Economic problems were ranked forth, and political-legal factors were still the problems despite the existence of sound policies in the country according to $112(56 \%)$ of respondents.

\section{SUMMARY OF THE MAJOR FINDINGS}

$\checkmark$ Women were found to have low experiences and exposure in the educational leadership area;

$\checkmark$ Women were found to have low self-confidence, self-esteem, and self-efficacy;

$\checkmark$ Women had low professional love or interest;

$\checkmark$ women were overburdened by institutional and house chores;

$\checkmark$ women were less qualified and also the number of women specialized in educational leadership was insignificant;

$\checkmark$ women was no networking among women themselves;

$\checkmark$ women had less competence and commitment,

$\checkmark$ women were found to be legally illiterate about their rights;

$\checkmark$ The women who had already held the top level positions were found to act against other women---queen bee syndrome;

$\checkmark$ Women were found to be highly socialized into the negative attitude of the society;

$\checkmark$ Attitudes of women towards their natural talents was found to be low;

$\checkmark$ There still was prevalence of sex stereotype, glass ceiling, and women were still overburdened with house chores, and also there existed discouraging negative attitudes, expressions, and proverbs against women in the society;

$\checkmark$ Though affirmative actions were practical, however, there was an imbalance between the policy and the implementation;

$\checkmark$ Women were not legally supported and empowered practically though there were different advocacy works on the part of both government and non-governmental workers;

$\checkmark$ Women were witnessed to be of economically poor family backgrounds and sources of economy; 
$\checkmark$ Infrastructure and payment for women at lower positions of work were found to be low;

$\checkmark$ There was low attempt made to advance women by the institutions;

$\checkmark$ There was male violence and high burden of work in educational institutions for women;

$\checkmark$ The system was not developed to empower women leaders institutionally;

$\checkmark$ There was no attempt made to organize women forum;

$\checkmark$ Facilities and materials provided for women were not promising;

$\checkmark$ There were no transparent recruitment and promotion policies in schools, clusters and district education offices;

$\checkmark$ There were no model women leaders in the two zones and women were not motivated to come up to the leadership positions in the education sectors in the two administrative zones of Dawro and Wolaita zones;

$\checkmark$ There were no attractive incentives and salary that could have retained and attracted women in the education sector;

$\checkmark$ No strategy was designed to promote women to the leadership positions in the education sector;

$\checkmark$ Male counterparts for women had low confidence in the leadership competency of women;

$\checkmark$ Women were denied of the advanced leadership training by institutions;

$\checkmark$ Women held precarious leadership positions;

$\checkmark$ Low interest was shown by the concerned bodies to breed potential women leaders in the education sector of the two zones;

$\checkmark$ Top male leaders did not have awareness about the talents and significance of women leaders;

$\checkmark$ There were low attention given for the importance of mentors for the development women potential leaders;

$\checkmark$ Glass-cliff was also observed in educational institutions and community;

$\checkmark$ Leadership diversity issue has got low concern on the part of institutions, and also the low co-operation among women themselves was observed.

\section{CONCLUSIONS}

$\checkmark$ The findings showed that women in educational leadership positions as principals, supervisors, and district education offices in the two catchment zones of Dawro and Wolaita administrative zones were underrepresented because of institutional factors, women themselves related factors, socio-cultural factors, political-legal factors, and economic-technological factors. Thus, this indicated that authorities failed to understand the benefit of leadership diversity in organizations to bring about change for women themselves, institutions and the large society as well.

$\checkmark$ Institutional problems were ranked first. This indicated that institutions failed to understand a number of advantages that women have both for the organizations and the country as well.

$\checkmark$ Women were found not to have freed themselves. Though there were women policies and women supportive issues were stipulated in constitutions, women couldn't come up to the leadership positions. This indicated that they have still been socialized in to the negative attitudes societies had over women.

$\checkmark$ There was still negative attitude on the part of the large society regarding women leadership. Thus, it was concluded that awareness creation still remains in the society as an area of concern by the government and society as well. 
$\checkmark$ Though there were a number of affirmative actions and advocacy work, however, it could be concluded that the government and other concerned bodies were left with a number of assignments regarding empowering women.

$\checkmark$ Though economic factors were ranked the last, yet more than half of the respondents witnessed that it was still the problem for the underrepresentation of women in education sectors of the two administrative zones of Dawro and Wolaita. Hence, this showed that the government and other concerned bodies were left with assignments regarding empowering women economically through amendments of different labor laws and property policies of the country.

\section{RECOMMENDATIONS}

$\checkmark$ The pool of educated women that is the potential sources of aspiring women leaders is not full. Therefore, all the concerned bodies-the government, the society, the institutions and women themselves should strive towards accessing education for women taking into account that women are half of the population.

$\checkmark$ It is learnt that the government has designed a sound policy on gender. However, women are seen not to have exhaustively used it. So, taking into account that no one can free them if they fail to empower them, they have to work hard to be empowered. They have to create network with others; they have to avoid marginalization and socialization into the societal negative attitude, and more they have to exhaustively use constitutional rights.

$\checkmark$ Institutions are found not to be supportive towards empowering women. Therefore, taking into account that they are half of the population and that they are talented to leadership as men, should make the work environment conducive for the aspiring women for leadership through the provision of different leadership capacity building trainings and availing different relevant materials for women.

$\checkmark$ Most already empowered women of the society were found to be hostile (queen bee syndrome) for the other leadership aspiring women. Therefore, they have to be made to avoid such bad habits taking into account that the presence of more women in leadership positions has a number of advantages for both the women and the society.

$\checkmark$ There have been observed a number of affirmative measures for women in empowering. However, there observed that there is still the gap in implementation of the policy.

$\checkmark$ Most of the women were found to be legally illiterate-they do not know exhaustively the rights that stipulated even in the constitution of the country. They still feel inferiority complex and submissiveness. Therefore, advocacy programs and awareness creation should be made continuously.

$\checkmark$ Mentoring and coaching programs of women academic staff by particularly women mentors should be made to capacitate the leadership aspiring women.

$\checkmark$ Girls should be assigned as chair persons or secretaries in different curricular and cocurricular activities like clubs so that to practice leadership from the very beginning in schools to avoid fear and socialization into the bad and negative attitudes by the society.

$\checkmark$ It was observed that there were no women federation though there was student parliament recently established and though there are differences among this. Therefore, schools should strengthen this along with other relevant activities towards women.

$\checkmark$ Women are found to hold many precarious positions in the education system. Therefore attempts should be made to bring them to the leadership positions through different trainings.

$\checkmark$ Organizational cultures in some schools were found to against empowering women. Therefore the government, large society and women themselves, and the non- 
governmental organizations as well should give their ears to empower women at different levels in the education sectors including schools.

$\checkmark$ A number of literature and scholars tell that women have unique brain architecture, are naturally talented to leadership, and have unique leadership qualities. However, most male leaders who have assumed the leadership positions are not aware about that or not willing to bring that quality of women to the front. Therefore, taking this into account that women leaders are the missing spices of work in general and leadership in particular in population, all the concerned should do to empower women.

$\checkmark$ Though different economic policies are formulated and empowering women became the motto of nations and ILO, however, women are still deprived of being owners of properties. This highly hindered their freedom even to learn as they wanted. So, different economic policies regarding women should be put on the ground.

\section{References}

Airini, C.S.(2011). Learning to be Leaders in Higher Education: what helps or hinders women's Advancement as leaders in universities.

Best, W.J. and V.J.( 2003). Research in Education, New Delhi: Prentice Hall.

Booysen, L. (2007). Barriers to Employment Equity implementation and retention of blacks in management in South Africa. South African Journal of Labor Relations, 31(1), 47-71.

Chiloane-Tsoka, G. E. (2010). Perceptions of barriers to the advancement of women in management and leadership positions in South Africa. Journal of Gender and Behavior, 8(2), 2976-2995.

Creswell, J. W. (2009). Research design: Qualitative, quantitative, and mixed methods approaches (3rd ed.). Thousand Oaks, CA: Sage.

Eagly, A.H. and Carli, L.L.(2007). "The Female Leadership Advantage: An evaluation of the evidence", The Leadership Quarterly, September: 807-834. Emebet,

FAWE (2010). Supporting Girls and Women to Education: Acquire Education for Development: Guidelines and Support for National Chapters, Nairobi: Kenya.

Greeff, M. (2011). Information collection: Interviewing. In A. S. de Vos, H. Strydom, C. B. Fouche, \& C. S. L. Delport (Eds.), Research at grass roots (pp. 341-374). Pretoria, South Africa: Van Schaik.

Helgeson, V. (2005). Psychology of Gender, New Jersey: person education ,Inc.

Irby, B.J. (2008). The Synergistic Leadership Theory. Journal of Educational Administration, 40(4), 304,6,7,10,12.

Johnson, Z. (2010). Investigating the existence of the Queen Bee Syndrome within the Banking Industry of South Africa. A Master's Thesis.

Koontz, H. and H. Weihrich (1988). Management, New York: McGraw Hill book company.

Kouzes, J. and Posner, B. (2010). The Leadership Challenges, New York: Josey-Bass.

MOE (1994). New Education and Training Policy, Addis Ababa: EMPDA.

Morley, I. (2006). Hidden Transcripts:The Micropolitics of gender in common wealth universities, women's studies International Forum, 29, 543-551.

Nkomo, M. and Ngambi, H. (2009). African women in Leadership: current Knowledge and a framework for future studies. International Journal of African Renaissance Studies. 4, 49-68.

Onsongo, J. (2006). GenderIn equalities in Universities in Kenya. Retrived from http://(213.55.113.32) at 05.1: 1901 October 2018.

Otunga, A. and Ojwang, A. (2004). Women and Leadership Position in Higher Education, 27 park end Street, Oxford: African Books Collective.

Schertzer, C.S., and Stone, B. (1980). Fundamentals of Counseling, Boston: Houton Miffin Company.

Schuler, A.M. and Sakuntala, K.R. (1992). Legal Literacy: A Total for Women's Empowerment, Washington, D.C.: African Publisher.

Schurink, W., F. et al. (2011). Qualitative data analysis and interpretation. In A. S. de Vos, H. Strydom, C. B. Fouche, \& C. S. L. Delport (Eds.), Research at grass roots (pp. 397-423). Pretoria, South Africa: Van Schaik. 
Shake shaft, C. (2007. Women in Educational Administration, New Delhi: Sage Publication Inc.

Singh, A. (2012). Coaching female leaders in a male-dominated environment: Stress management through selfawareness and reflection. (Unpublished master's dissertation). University of Stellenbosch, South Africa: Singleton, R. A. Jr., \& Straits, B. C. (2010). Approaches to social research (5th ed.). New York, NY: Oxford University Press.

Strydom, H. (2011). Ethical aspects of research in the social sciences and human service professions. In A. S. de Vos, H. Strydom, C. B. Fouche, \& C. S. L. Delport (Eds.), Research at grass roots (pp.113-129). Pretoria, South Africa: Van Schaik

Transitional Government of Ethiopia (1993). National Policy on Ethiopian Women, Addis Ababa: Prime Minister's Office on Women's Affairs.

Tyson ,L.D. et al.(2012). The Global Gender Gap Report. Berkeley: California

UNESCO (1994). Education of Girls and Women beyond Access: contribution of UNESCO to the fifth African Regional Conference on Women. Dakar: Senegal.

(1996). Guide to Teaching and Learning in Higher Education, Breda: Dakar.

Wassenaar, D. (2010). Ethical issues in social science research. In M. Terre Blanche, K. Durrheim, \& D. Painter (Eds.), Research in practice: Applied methods for social sciences (pp. 60-79). Cape Town, South Africa: University of Cape Town Press.

World Bank(2012). Thepartnership on Sustainable Strategies for Girls' Education, Washington, D.C.

Yukl, G. 2006. Leadership in Organizations. 6th ed. New York: Pearson Prentice-Hall. 